\title{
FVA and Electricity Bill Valuation Adjustment-Much of a Difference?
}

\author{
Damiano Brigo, Christian P. Fries, John Hull, Matthias Scherer, \\ Daniel Sommer and Ralf Werner
}

\begin{abstract}
Pricing counterparty credit risk, although being in the focus for almost a decade by now, is far from being resolved. It is highly controversial if any valuation adjustment besides the basic CVA should be taken into account, and if so, for what purpose. Even today, the handling of CVA, DVA, FVA, ... differs between the regulatory, the accounting, and the economic point of view. Eventually, if an agreement is reached that CVA has to be taken into account, it remains unclear if CVA can be modelled linearly, or if nonlinear models need to be resorted to. Finally, industry practice and implementation differ in several aspects. Hence, a unified theory and treatment of FVA and alike is not yet tangible. The conference Challenges in Derivatives Markets, held at Technische Universität München in March/April 2015, featured a panel discussion with panelists representing different points of view: John
\end{abstract}

\author{
D. Brigo $(\varangle)$ \\ Department of Mathematics, Imperial College London, London, UK \\ e-mail: damiano.brigo@imperial.ac.uk \\ C.P. Fries \\ Department of Mathematics, LMU Munich, Theresienstrasse 39, \\ 80333 Munich, Germany \\ e-mail: christian.fries@math.lmu.de \\ J. Hull \\ Joseph L. Rotman School of Management, University of Toronto, 105 St George St, \\ Toronto, ON M5S 3E6, Canada \\ e-mail: hull@rotman.utoronto.ca \\ M. Scherer \\ Lehrstuhl für Finanzmathematik, Technische Universität München, Parkring 11, 85748 \\ Garching-Hochbrück, Germany \\ e-mail: scherer@tum.de \\ D. Sommer \\ KPMG Financial Risk Management, The Squaire am Flughafen, 60549 \\ Frankfurt, Germany \\ e-mail: dsommer@kpmg.com \\ R. Werner \\ Professur für Wirtschaftsmathematik, Universität Augsburg, \\ Universitätsstraße 14, 86159 Augsburg, Germany \\ e-mail: ralf.werner@math.uni-augsburg.de


Hull, who argues that FVA might not exist at all; in contrast to Christian Fries, who sees the need of all relevant costs to be covered within valuation but not within adjustments. Damiano Brigo emphasises the nonlinearity of (most) valuation adjustments and is concerned about overlapping adjustments and double-counting. Finally, Daniel Sommer puts the exit price in the focus. The following (mildly edited) record of the panel discussion repeats the main arguments of the discussants-ultimately culminating in the awareness that if everybody charges an electricity bill valuation adjustment, it has to become part of any quoted price.

Keywords Counterparty credit risk $\cdot$ Credit valuation adjustment $\cdot$ Debit valuation adjustment $\cdot$ Wrong way risk

\section{Welcome}

Matthias: Welcome back from the coffee break. After the many interesting talks we already enjoyed today, we will now continue the conference with a panel discussion on current issues in counterparty credit risk. And we are very proud to present you such prestigious speakers on this topic_-our anchorman Ralf Werner will introduce them to you in a minute (Fig. 1).

We hope that this discussion will provide you with insights on the current discussion about CVA, DVA, FVA, etc. that go beyond what you can read in scientific papers. In my personal view, these valuation adjustments are a special topic in financial mathematics, because they are not simply expressed by formulas some mathematicians invent and you implement in a spreadsheet. In contrast, these adjustments are chal-

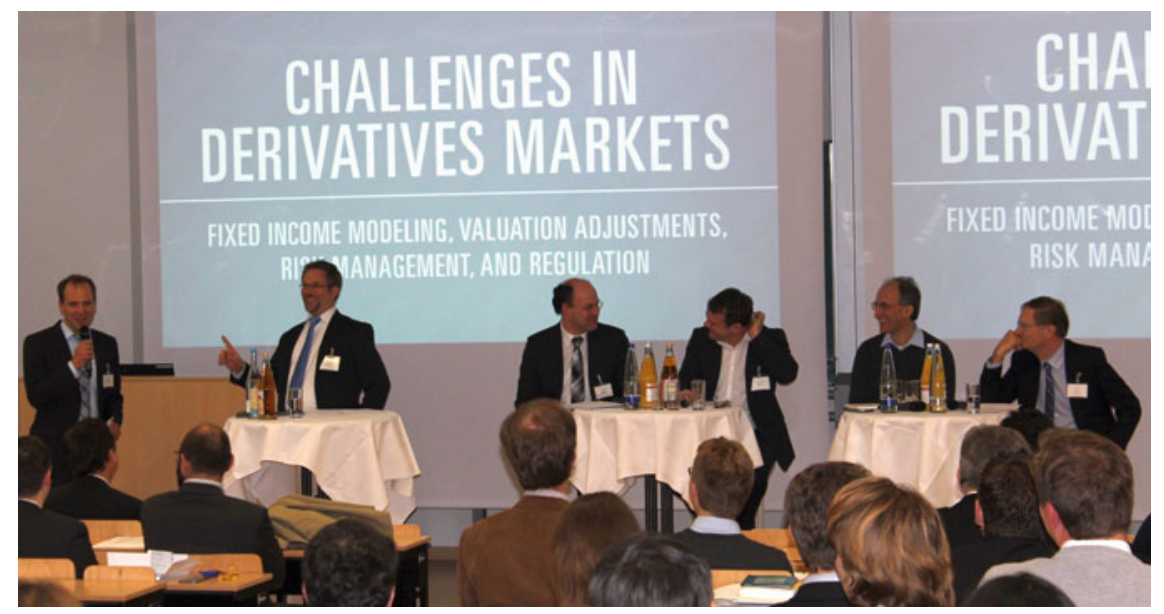

Fig. 1 View on the panel. From left to right: Matthias, Ralf, Daniel, Christian, Damiano, and John 
lenges a whole bank has to work on as a team, because they can involve different departments, different asset classes, different trading desks, the IT-infrastructure, lots of data, etc. Hence, it is not something that is "done" after a scientific paper has been published. Moreover, there is no consensus-neither in academia nor in practice-on what adjustments should be used and how they must be computed. In this regard, I am very happy to see representatives from the financial industry as well as from academia gathering for this discussion.

I will now pass the microphone to Ralf Werner who will be our anchorman. Ralf is professor for "Wirtschaftsmathematik" at Augsburg University. Prior to this he was professor at the University of Applied Sciences in Munich, and prior to this he worked for several financial institutions_-most of which have defaulted.

Ralf: Yes, indeed. Three in total.

Matthias: In any case, he gained quite some experience-practical and theoretical-with credit defaults that he is now sharing with you. Thank you very much Ralf!

Ralf: Thank you, Matthias, and a warm welcome to everybody from my side. I'm very honoured to chair this discussion. I don't think I will need to do much because we already had an excellent warm-up over lunchtime, and my experience is that these four experts in the panel won't need much input from my side to keep the discussions controversial, yet fruitful.

For the unlikely event that the discussion might get stuck, we have prepared a few additional questions. Further, any question or comment from the audience will be addressed immediately, i.e. we will interrupt whenever possible and whenever meaningful.

The idea is that each discussant has about ten minutes to address one or more topics he deems important. I'll try to dig a bit deeper and if you like you join in asking and eventually after 15 minutes we hand over to the next discussant. This means that in one hour we should be able to pretty much cover everything concerning DVA, FVA, CVA, multi-curve, whatsoever, within the scope of the conference.

Let me now introduce the participants in reverse alphabetical order. I would like to start with Daniel Sommer to my left. Daniel is not only representing one of the main sponsors of this conference, but he's further representing almost 20 years of experience in financial consulting. Daniel is a member of the financial risk management group at KPMG, and for more than ten years he's responsible partner for risk methodology. Daniel holds a PhD on interest-rate models from the University of Bonn, he has published several papers, he is working for all major banks in Germany, so in short he comes with a broad experience of what's going on in the market. I think this is an excellent opportunity for us to challenge his knowledge and his experience.

On the other end of the panel we have John Hull. I both asked John as well as Damiano during the lunch break, and we agreed that re-introducing both of them after we had such great and detailed introductions this morning prior to their talks is saying the same thing twice over. John will hopefully talk a bit about FVA, and I assume all of you have read his 2012 paper, see [7]. If not, my introduction may last another $60 \mathrm{~s}$, so please at least run through the abstract of this great paper. It's an excellent work, starting heavy discussions in the community, I'd like to say-fruitful 
discussions, raising lots of interesting questions on FVA: Is it really there? Should it be zero or not? For me, somehow, the discussion is not yet over, so I am looking forward to what John has to say.

Besides John, between Daniel and Damiano, we have Christian Fries, our local panel member from the LMU. Christian was appointed professor for Financial Mathematics a few years ago. I should emphasise that besides his academic duties he is still mainly working at DZ BANK where he is responsible for model development, heading this department. Of course, I think you all know Christian from his opensource library and from his book, resp. on Monte Carlo methods in finance [5], and I'm sure we will gain a lot of insight from this mixed-role in practice and academia.

And, finally, we have Damiano Brigo with us, whom I would like to start right away without any further notice, so please, Damiano.

\section{Damiano Brigo}

Damiano: Okay, thank you. I made some of the points during the presentation, but I think it's worth summing up a little bit what's been happening from my point of view. I worked on what is now called CVA since, I think, 2002 or 2003 at the bank. At the time it was called counterparty risk pricing, not CVA, and nobody was really very interested because the spreads were small for most of the trades and so on, so the work was recycled a few years later, especially in 2007. But as we did that it was clear that this was only a small part of a much broader picture where we had to update the valuation paradigms used in investment banking and not only there (Fig. 2).

The big point that seems to come out, at least methodologically, from that big picture is nonlinearity, which shows up in a number of aspects that can or may be neglected in many cases but not always. So one of the aspects is the close-out, what

Fig. 2 Damiano Brigo giving his presentation on "Nonlinear valuation under credit gap risk, collateral margins, funding costs, and multiple curves"

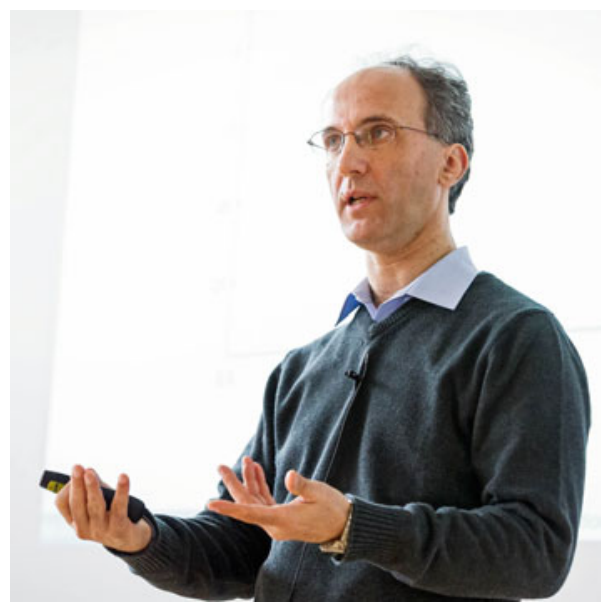


happens at default. What do you put in your simulation? Should you use a risk-free close-out, where at the first default you just stop and present-value the remaining cash flows without including any further credit, collateral, and funding liquidity effects? Or should you rather use a replacement closeout, where those effects are all included in the valuation at default?

This is a big question. If you go for the replacement, then the problem as we have seen becomes recursive, if you like, or nonlinear from a different point of view. And that's not because we mathematicians are trying to push BSDEs or semi-linear PDEs on you. It's simply because of the accounting assumptions. It's a basic fact, an accounting rule that says that you have to value your deal at default using a replacement value. This is a simple accounting rule, but it translates into a quite nightmarish nonlinear constraint in the valuation. Then when borrowing and lending rates are asymmetric in financing your hedge, if they are justified to be, then you have another source of nonlinearity because to price these costs of carry you need to know the future value of the hedge accounts and of the trade itself. And this induces another component of nonlinearity (see [4] and [3]).

If it's there or not depends on the funding model you adopt for your treasury. If the trading desk is always net borrowing and possible liquidity bases are symmetric, you don't have that, and you can more or less have a symmetric problem, but if it's not net borrowing then you do have an asymmetry in the funding rate: one is the credit risk of your bank, one is the credit risk of the external funder, plus liquidity bases. So, we all know that borrowing and lending don't happen at the same rates usually (well, we experience it personally, at least).

So, the nonlinearity is there. The big question is Should we embrace it or keep it at arm's length?, because it makes things too complicated in practice. The answer is the second one, and basically if there is any real nonlinearity in the picture, the required methods like BSDE's or semilinear PDE's are very hard to implement on large portfolios in an efficient way that ensures that you can value the book many times during trading activity very quickly-especially because nonlinearity means the price or the value is not obtained by adding up the values of the assets in the portfolio, so you need to price the portfolios at all the possible aggregation levels that you need, and if each component of such a run is slow, you can imagine what kind of operational nightmare you get into. So I don't think it's realistic or feasible at the moment that we embrace nonlinearity. We need to linearise, which means, in the two cases I mentioned, we assume that borrowing and lending rates are the same, which is true for some funding policies, and you also assume that you don't use a replacement closeout at default in the CVA calculation of the valuation adjustment for credit.

Then the other problem I would mention is keeping all the risks in separate boxes with a label on each box: CVA: this is credit risk, FVA: this is funding cost, LVA: this is collateral cost and so on. This is a little misleading because these risks interact in the way that I just described. Each cash flow involves the whole future value which depends on all the risks together. The classification in boxes is useful managerially because you want to assign responsibility in an organisation; you cannot have everyone responsible for everything unless you have a very illuminated kind of 
workplace, but if you don't, you want to assign responsibility for credit risk to the CVA desk, and maybe the funding costs to a different team in the CVA or XVA desk and so on. But if these aspects are so connected as I said, it's very hard to separate the risks in different boxes. Wrong-way risk is another aspect of the fact that the dependence makes the idea that you can have risk taken care of separately by the CVA desk for credit risk and by the traditional trading desk for the trade main market risk not very realistic. To some extent, you can do it, but it's not precise.

So, these are labels that we apply in order to be able to work operationally in a realistic setting, but they don't have the amount of rigour or precision that we would sometimes think they have in practice. So, should we, again, monitor and watch out for manifestations of nonlinearity like overlapping adjustments? We saw that in some set-ups DVA almost completely overlaps with the funding adjustment. And, so, should we be aware of these and avoid the double-counting, or should we forget it and just compute the different adjustments, add them up, and forget about all these overlaps and analyses?

I think it's important to have at least an initial understanding of these issues before throwing ourselves into very difficult calculations. There are many other things I could say. The nonlinearity makes the deal pricing very difficult_-in funding costs especially. When you don't know the funding policy of the other institution, or maybe you don't agree with the funding policy of the other institution, but you're still asked to pay their funding prices, you might object and go to another bank, or you might in turn say, I also have some funding costs, and I want to charge you. And there is no transparency in the funding model of the treasury process. How can bilateral valuation be achieved in a transparent way? This is another problem.

So a number of authors conclude by saying the funding-adjusted value is a value; it's not a price. You can use it for profitability analysis internally, but you shouldn't charge it outright to a client because it's hard to justify this charge fully, as we have seen. On the other hand and this is the final point I want to raise, which is kind of a meta-topic, I would like to talk about the self-fulfilling aspect in financial methodology, that if two or three top banks start doing something, everybody else follows because this becomes the new standard. Top bank $A$ is doing this, top bank $B$ is doing this, so we have to do this as well. And then even if something is not justified based on financial principles, or it is not reasonable methodologically or even mathematically it doesn't matter because if you don't do it you place yourself out of the market.

This is very frustrating for a scientist, for someone who thinks there are underlying sound principles behind what's going on, but in the end you are forced to set the problem aside, because that's what the market is doing, and if you don't follow, you are automatically out.

I would like to conclude with that kind of provocative point, and I'm sure my colleagues will have more interesting points to make on it. Thank you. 
Ralf: Thank you, Damiano. Is there anyone in the panel who wants to take up one of these points? Or in the audience?

Christian: I'd like to ask you, Damiano: you said close-out value. This is a very important discussion. So, from my point of view, is this an issue for the lawyers, or is this an issue for financial mathematics? What would you say?

Damiano: I think it's an issue for both in a sense, in that the lawyers should tell us if it makes sense to have this close-out there or not based on legal considerations. In the end, I don't think we can decide this with mathematics alone. With mathematics we can say, If you adopt this close-out, the valuation problem is like this, and if you adopt this other, the valuation problem is like that, but the decision must be taken based on accounting, financial, and legal principles, not based on mathematics.

I would say that the regulations should converge. We've had ISDA pushing a little towards the replacement close-out, but very mildly. ISDA wrote in 2009 that in determining a close-out amount, the determining party may consider any relevant information, including quotations (either firm or indicative) for replacement transactions supplied by one or more third parties (!) that may take into account the creditworthiness of the determining party at the time the quotation is provided (notice the use of may). In the end I think it's a decision for the regulators and the policymakers. We discussed this earlier, but let me be more explicit. Are you thinking, with respect to your operational model, let's say, when the deal has defaulted do you think to actually replace it with a new one or simply to liquidate everything and close the position? This is the real question. If you think to replace it with another physical deal, and you intend to re-start the trade with another contracting party, then you should assume a replacement close-out. If you're thinking of liquidating the position, then it stops here, with a cash settlement, and you may use a risk-free closeout. However, from the point of view of continuity, mathematics seems to suggest that you should include the replacement because you value the trade, mark it to market every day, including credit and funding costs, and all of a sudden at the default event, you remove this. You create a discontinuity in valuation this way, which shows up as some funny effect, which I don't want to go into right now.

I think mathematics gives you some hint, but it's really a regulatory / accounting / legal discussion that we should have, and then use the maths to include the outcome properly into the valuation. That's my view.

Ralf: Let me exaggerate a bit, but will this lead into a situation where your line of reasoning is also applied to mortgages or government debt? Would Greece say, I'll only pay 60 because I'm valued at 50 anyway, so this is the right replacement value? Will this lead us into such kind of discussions?

Damiano: That is very hard to model because when you have such a large market effect, then the close-out itself could change the economy basically, so I don't think it's very realistic in that sense.

In fact, we found in the published paper [1] that there is no superior close-out. If you use the replacement close-out, you have some advantages in terms of continuity and consistency, but you'll have some problems when the correlation goes up towards the systemic risk scenario. In that case the risk-free close-out becomes more sensible economically. There is no clear-cut case, and you cannot make a regulation that 
depends on correlation or the level of perceived systemic risk switching from one close-out to the other. Can you imagine what happens when you are in the middle. I don't even want to go there (see [2]).

So I think we have to be very careful about the maths, and we have to clearly understand which level of aggregation, of size, we're talking about, and in the case of a country, I think that would be quite dangerous.

Daniel: I agree.

Damiano: At the global derivatives conference a couple of years ago, I was talking to some of the banking quants and I said, Which close-out are you using?, and they would say We're using the risk-free close-out because that's the only thing we can implement on a large portfolio.

Ralf: I agree. I've heard this is hidden in the recovery rate, anyway.

Christian: So maybe I'd like to comment or offer a question on this self-fulfilling prophecy because I do not understand it. I do understand that if there is some idiot in the market who's trading options at the wrong price, then I can use his incorrect pricing to have an implied volatility. Hence, I can imply his dumbness into my model and that's fine. But now you say that everybody is doing it, so we should do it. And I believe this does not apply to FVA. For me, FVA is a real cost and, for example, the market will now decree not to account for FVA, I still picture that I have lost, for example, if I issue a bond at LIBOR plus spread, and just put the money to the ECB for a zero interest rate, I have a loss, right? So, then I would say I would rather go out of the market instead of making the loss.

Damiano: Okay, so let me ask you another question. Suppose electricity bills become prohibitive and electricity skyrockets, will you start charging your client an electricity bill valuation adjustment because that's a real cost you're having? Or will this be embedded in the prices like in the old days.

Christian: It is.

Damiano: When you go and buy some bread from the baker, the baker doesn't charge you a running water and electricity bill valuation adjustment because he needs some water to run his bakery, you know ...

Christian: Yeah, but if you go to the bakery, he charges you such that he is covering all his costs.

Damiano: That's right.

Christian: It's just not transparent.

Damiano: That's right.

Christian: But the cost is inside the price.

Damiano: But then if you add these valuation adjustments one by one, one after the next, every year a new one, with the nonlinearity effects we see that they possibly overlap, you are overcharging sometimes, and this is not good, and that's what I feel is happening.

KVA. Think about it. KVA is a valuation adjustment on capital requirements, but the future CVA potential losses trigger capital requirements-so you have your valuation adjustment on a valuation adjustment. This is getting out of hand. 
Christian: This point I understand, but that is regulatory ...

Damiano: But going back to the self-fulfilling prophecy, the other thing I wanted to say: think about base correlation. For CDOs base correlation is a model. You use a Gaussian copula, flatten 7,750 correlations into one, apply different flat correlations to each different tranche on the same pool. To explain a panel of 15 CDOs you have 15 different and inconsistent models and then ... I kid you not, once at an international conference I met one quant from a top bank who was lecturing about base correlation along the lines of here's an example of calibration, this is a great model, you should use it, CDOs are great, invest in this. And when I asked, after his talk, I have some questions for you about this model, he'd say, Oh, I'm the marketing quant. I don't do models really. And I said, Take me to your leader!, meaning the real quants then, and he said, Oh, you cannot talk to them; they don't talk to the public. My function is to convince people, investors and the market that this is a great model, this is a great product, and everybody must come into this market.

However what you are saying is partly true. If the market is kind of complete in a way, then by hedging your strategy according to the correct hedge you can prove that your price is right against an opponent, but if the market is largely incomplete, this is very hard to do. And this is what we look at when we look at funding costs. We don't know the hedging or the funding policy of another entity. It's not transparent. You don't know what they're doing, how they're financing, their short-term/longterm funding policy, their internal fund transfer pricing, their bases. You don't know many things.

Christian: This is exactly the point. The market is not complete here, and I cannot pass this risk to someone else. This is my example with the volatility: if someone is on the wrong volatility I can pass this risk to him, but with my funding it's still my risk and it's my cost to cover it. I believe it has to be in there. If you make it transparent, it's something different, maybe.

Damiano: Okay, but then you have to really watch out for the overlap as you add new risk. For example, in some formulations if you take into account the trading DVA and also the full funding benefit, you have the same thing twice. You have to be very careful there. So this practice of adding a new adjustment on top of the old ones every year is very dangerous because you may miss some of the overlaps. The banks are paying attention to it; it's not that bad. If it develops in the fact that in ten years we'll have 15 new valuation adjustment, this will be out of control.

Audience member: I have a question because I really like this bakery example, so let's say you have one bakery who sells bread for 1.80 and who doesn't have very high electricity costs, and you have another bakery which sells it for 2.00 because they have a lot higher electricity costs. So what is the market price, then? Is it 1.80 ?

Damiano: The price, if you look at a clean price versus an adjusted price, the price would be the clean price without costs. But then, of course, the price is adjusted into an operational price that takes into account the bill, but the bill is not quoted explicitly, it's embedded in the price, so that if you think this baker is too expensive, you'll go to the other one. Maybe the other one is out of town, so they have lower costs because of that. 
But in the other industries, we always knew that the price of a good that you end up buying depends on many circumstances that are not in a theoretical price in a way. Somehow ironically, part of the finance industry arrived at this realisation quite late. But that's another matter. I took too much time and I don't want to monopolise this panel.

John: Don't forget that we have bid-offer spreads in this industry. Those bid-offer spreads are designed to cover overhead costs, so adding in costs for electricity and other things is not really the way to do it.

Ralf: Thank you, John. Let me hand over to Christian. Christian, maybe you want to tell us your opinion on what's going on in financial institutions at the moment. Maybe with some more focus on the practitioner's point of view.

\section{Christian Fries}

Christian: You've asked me to make a few statements and I take the role of the practitioner.

I have the same opinion as Damiano, but I'd like to make the point that I don't like the adjustments. And why? Maybe because the word "adjustment" already implies that you did something wrong. If I have to adjust something, it tells me that the original value is wrong. For example, in my car there is this small device that tells me how long it takes to get from Frankfurt to Munich, and what would I like to see there? With my car it takes five hours. I could also fly. It would take one hour if you take the plane, but you have to add four hours' adjustment. So I would prefer just to see the five because the five is correct. The one hour is no information for me.

Then, let me give you another example. Consider a swap which exchanges LIBOR against a fixed rate, and this swap is traded at a bank, usually at a swap desk, sometimes it's called flow trading. And then we have another swap that exchanges LIBOR capped and floored against the fixed rate; this swap is called a structured swap, and it's traded at a different desk. This desk is sometimes called nonlinear trading desk because these people are doing the nonlinear stuff, but except sometimes for information purposes, we do not express the price of the swap as the price of the linear product plus the nonlinear trading premium. So there is no such thing as an option-valuation adjustment, so we do not have an OVA or something like that.

Daniel: Going back a few years, people tried to calculate option-adjusted bond spreads.

Christian: Yes, I know, and I am sometimes reminded of it. And so there is one desk in the bank that is taking the responsibility for all this complex stuff. This desk is also making transactions through the swap desk because the desk needs to hedge its interest rate risk, so he's hedging out all linear stuff to the other guys, and he keeps all the nonlinear risks. Let me make a remark about FVA; I will come back to CVA. For me FVA has a strong analogy to cross-currency, to multi-currency models-at least if you have the same rate for borrowing and lending. Each issuer has its own currency. So what is his currency? His currency is the bond he's issuing. Everything has to be 
denominated in his own interest rate, his funding rate. There are even instruments on the market which profit from this arbitrage between two banks which have different funding. These are the total return swaps where one bank with poor funding goes to another bank with good funding and they exchange funding and they both profit from this deal. I mean, the market for total return swaps is currently dead because funding is for free, but these things existed. I have a little paper with my colleague Mark Lichtner on this (see [6]).

This currency analogy: we had this in multi-currencies for years. We know how to value instruments in different currencies, and we have the same phenomena in currencies. For example, the cross-currency swap exchanges a floating rate in one currency for a floating rate in another currency. From the theory, this should be zero: both are floaters which are at par, but cross-currency swaps trade at a premium. There is a cross-currency basis spread. The reason is that there is a preference in the market, that one likes to finance oneself in U.S. Dollars and not in Euros (or vice versa), so, for example, a Euro bank would prefer to go to Euro financing instead of U.S. Dollar financing. I believe that FVA is something very natural. Also in mathematical theory it has been there in this currency analogy since, and it should be recognised inside the valuation because we wouldn't value Euro derivatives using the U.S. Dollar curve, would we?

One more word to CVA. If I'm provocative, I would say, like Damiano already pointed out, counterparty risk isn't something new. We had a defaultable LIBOR market model years ago, and counterparty risk was used years ago maybe only for credit derivatives, but it's not so new, and what is actually new here is that we suddenly have to look at netting. So the big change for me in this valuation adjustment topic is that we are talking about portfolio effects. What Damiano said this morning: the sum of each individual product valuation doesn't give you the value of the portfolio. So you have portfolio effects, you have to value everything in a single huge valuation framework, but if you define all the products of a bank as a portfolio, as one single product-I believe that the theory to be able to do this is actually to some extent known-the big problem is how do you implement numerically what you do on the computational side. For me this is the main motivation for these valuation adjustments. It is because we have computational problems, and we like to decompose the valuations into valuations for which we can sum up the products.

Going back to FVA, I do not understand why many people still use the risk-free interest rate as the basis for this valuation, for your reference valuation-because, first of all, I don't believe there's such a thing as a risk-free interest rate; it's just a misnomer. And wouldn't it be better to keep the adjustments as small as possible such that the price which you calculate is already as close as possible to the true price? So, for example, my navigation system in the car tells me, from Frankfurt to Munich you need four hours and thirty minutes. Okay, when I drive you need five hours and thirty minutes, but it gives me a good proxy. The proxy is using the average information available.

So coming back to Damiano's talk, maybe we should simplify things. I like to have things simplified, and my question is how can you simplify things such that you can implement them in a bank. For example, we can simplify and say that treasury 
uses an average funding rate which is in the middle of the bid-offer, and we use that rate to calculate the funding costs so that we have symmetry there and so on.

Finally, I would like to have just one desk where nonlinear effects are managed. We could have this set-up, so the question is how can we have this set-up in a bank. We could have this set-up if we have internal transactions in the bank, and these transactions are fully collateralised. So we have these linear traders who trade collateralised transactions with this nonlinear trading desk, and the nonlinear trading desk has the residual.

My conclusion is that I would like to have one formula or one model which gives me the true price, and then we can set up internal transactions, but what is the good way to set up these internal transactions such that we can implement this in a bank? This is my concern.

Audience member: Talking about implementation in the bank: What can you implement? Where is banking nowadays? CVA, we have all the data for CVA, I assume. No clue on wrong-way risk on these correlations you need and you already think about FVA and adjustments on adjustments but still didn't manage to find a decent proxy for wrong-way risk? The question is, are we looking and are we solving the right problems? What is your impression?

Christian: The data is actually the critical thing here. We can include more and more effects in a nonlinear trading valuation framework by improving the model-for example like the approaches we have seen here including wrong-way risk, copulas, whatever, but the problem is that we actually do not have the data to calibrate the model.

For example, going back to John's talk this morning, I have a little comment here: you'll see the effect of this multi-curve switch from LIBOR to OIS, but in this calculation there is an assumption. The assumption is that the swap, which is LIBOR-collateralised, so we use LIBOR discounting, trades at the same swap rate as the swap rate that is OIS-collateralised, so we use OIS discounting, so if you have the same rates for the swap, you get different forward rates. That's what we saw this morning.

The problem is you do not observe the swap rate for a LIBOR-collateralised swap. So it could even be that the swap rates are different and the forwards are the same. If we value, for example, an uncollateralised product, we do not even know what the correct forward rate is because we would need the uncollateralised swap to calibrate this forward rate. Data already start at the very beginning. The problem is data.

Ralf: Do you agree, Damiano?

Damiano: I talked to one of the CVA traders at a top tier 1 bank. They told me they have what they call zero-order risks in mind more than cross-gamma hedging. What they don't have for many counterparties is a healthy default-probability curve because there's no liquidity in the relevant CDS, so maybe they have a product with the airport of Duckburg, and this airport hasn't issued a liquid bond and there is no CDS. Where do you obtain the default probability? From the rating? But that's a physical measure, not a risk-neutral measure. And then the wrong-way correlations: you should use market-implied correlations because you are pricing, but then, where do you get them? It's almost impossible to get them for many assets, and also, finally, 
I would say that with CVA, you're right-we talk about KVA, but CVA is still very much a problem - and there is what I call payout risk, so depending on which closeout you use, and whether you include the first default check or not (some banks don't, because by avoiding it you avoid credit correlation, which is a bad beast in many cases), so depending on the type of CVA formula you implement-you have five, six different definitions of CVA - and that is payout risk. With old-style exotics, you had a very clear description of the payout, then you implemented the dynamics; you would get a price and hedge, and that would change with the model, and that would be model risk. Now with CVA we have payout risk. We don't even know which payout we are trading exactly, unless we have a very precise description of the CVA calculation.

But it's not like when you ask another bank, What CVA charge are you applying to me?, they tell you It's a first-to-default inclusive, risk-free closeout ... They don't tell you that. ... And I'm using this kind of CDS curve. Sometimes they don't tell you that, and you don't know.

Ralf: Daniel, do you have the same experience?

Daniel: Absolutely. I think even as many banks are talking about FVA these days, I think CVA is still an unresolved topic, and our observation is that even in a small market like the German market, there are a lot of different approaches taken by the banks to calculate CVA. The problem is becoming more difficult by the minute as the observable CDS prices, or tradable and liquid CDS prices get fewer and fewer. So this is an issue that gets more complicated by the minute.

And then another observation: we had a talk about wrong-way risk this morning, and we learned about the difficulties that this involves, and not surprisingly it's our observation that many banks are far from including wrong-way risk in their CVA calculations, so there's a long way to go before even CVA is settled.

Ralf: Okay, thank you very much, Daniel.

John: Maybe I should just respond to the point that Christian made about my presentation this morning. My swap rates were all fully collateralised swap rates, which would today reflect OIS discounting. I think Wolfgang [Rungaldier] called them the clean rates. As soon as you look at the uncollateralised market, any rates you see are contaminated by CVA and DVA.

You say, Use LIBOR discounting. I would say the correct thing to do even with uncollateralised transactions is still to use OIS discounting and calculate your CVA and DVA using spreads relative to the OIS curve. Forget about the LIBOR curve. The LIBOR curve is no longer appropriate for valuing derivatives. It could by chance be that LIBOR is the correct borrowing rate for the counterparty you're dealing with, but in most cases the borrowing rate of an uncollateralised end user is different from LIBOR, so LIBOR is not a relevant rate. I don't care whether we call the OIS rate the risk-free rate or not, but it is the best close-to-risk-free benchmark that we have.

Ralf: Thank you, John. It's now your turn, so please continue with your statement. 


\section{John Hull}

John: Hard to know where to start because I have written quite a bit on FVA in the last few years. I've actually consciously decided to stop doing it because I realise I could spend the whole of the rest of my academic career writing about this, and I'd never convince most people.

Actually, my interest in FVA has got an interesting history. In the middle of 2012, I got a call from the editor of Risk magazine saying, We're bringing out the 25th anniversary edition of Risk magazine. We'd like you to write an article for it. I agreed to write the article. (No academic ever says no to writing an article.) I asked What would you like me to write about? He said, We don't mind what you write about, so long as it's interesting to our readership. But, by the way, we need the article in three weeks.

I went down the corridor to discuss this with my colleague Alan White. We had a number of interesting ideas for the article. After two and a half weeks we settled on FVA. The trouble was that we then had only three days to write the article. In retrospect, I wish we'd had longer. So what did that article say? That article said, you should not make an FVA adjustment. I'll explain why in a minute. The reaction to the article was interesting. Usually when you write these articles, nothing much happens. You get maybe a little bit of a response from a few other academics. But in this case we were absolutely inundated with emails from people about this article. Two-thirds of emails were saying You're crazy. You don't know what you're talking about. Clearly there should be an FVA adjustment. We've been doing for a while now ... and so on.

The other one-third were a little bit more positive, and some of them even went so far as to say, We're glad someone's finally said this because we were a little uncomfortable with this FVA adjustment. And, of course, Risk magazine realised that this was an exciting topic for them, so they started organising conferences on FVA.

Two people from Royal Bank of Scotland wrote a rejoinder to our article, which appeared in the next issue of Risk. And we were invited to write a rejoinder to the rejoinder, and so it went on. It was a really crazy time.

What I very quickly found out was that: Alan and I had a different perspective from most of the people we were corresponding with on this, and the reason was that we've been trained in finance. We've moved from finance into derivatives, and most of the people we were talking to had moved from physics or mathematics into derivatives. One important idea in corporate finance is that when you're valuing an investment, the discount rate should be determined by the riskiness of the investment. How you finance the investments is not important. Whether you finance it with debt or equity, it's the riskiness of the investment that matters. In other words, you should separate out the funding from the valuation of the investment (Fig. 3).

That was where we were coming from. In the case of derivatives a complication is that we can use risk-neutral valuation, so we've got a nice way of doing the valuation, but that does not alter the basic argument. Expected cash flows that are directly related 
Fig. 3 John Hull giving his presentation on "OIS discounting, interest rate derivatives, and the modeling of stochastic interest rate spreads"

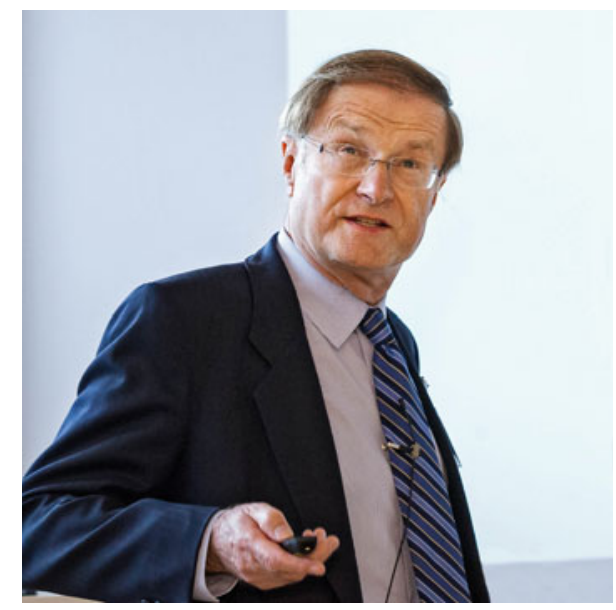

to the investment should be taken into account. In the case of derivative transactions these expected cash flows include CVA and DVA.

So that's where we were coming from. We've modified our opinion a little bit recently. I think I'm more or less in the same camp as Damiano here, judging by his presentation. Let's suppose that you fund at OIS plus 200 basis points. If the whole of the 200 basis points is compensation for default risk, then you are actually getting a benefit from that 200 basis points, in that that 200 basis points is reflecting the losses to the lender (and benefits to you) of a possible default on your borrowings. That is what we call DVA 2, and what Damiano called DVA(F), and other people have called it FDA. This is not what we usually think of as DVA. What we usually think of as DVA is the fact that as a bank you might default on your derivatives, and that could be a gain to you. Here we are applying the same idea to the bank's debt.

DVA 2 cancels out FVA, and that was the main argument we made in that Risk magazine article. But if you say that the bank's borrowing rate is OIS plus 200 basis points where 120 basis points is for default risk, and 80 basis points is for other things - maybe liquidity — we can argue that 80 basis points is a dead-weight cost. It's part of the cost of doing business, you're not getting any benefit from that 80 basis points. You are getting benefit from the 120 basis points: a DVA-type benefit because you can default on your funding.

So I think I am in the same camp as Damiano. I think he called it LVA. This component of your funding cost which is not related to default risk, is arguably a genuine FVA. The problem is, of course, that it's very, very difficult to separate out the bit of your funding cost that's due to default risk and the bit of your funding cost that's due to other things.

And then another complication is, of course, that accountants assume-for example when calculating CVA - the whole of your credit spread reflects default risk.

I have lots and lots of discussions with people on this. You realise very quickly that you're never going to convince somebody who's in a different mindset from 
yourself on this. One important question, though, is what are we trying to do here? With these sorts of adjustments, are we trying to calculate a price we should charge a customer? (Obviously in this day and age, we would be talking about the price we should charge an end user because transactions with other banks are going to be fully collateralised.) Or are we concerned with internal accounting? Or is it financial accounting that is our objective? I've always taken the view that what we're really talking about here is what we record in our books as the value of this derivative. But if you take the view that what we're trying to do is to work out what we should charge an end user, a customer, then actually I have no problems doing whatever you like, even trying to convince a customer that the customer should pay an ECA, an electricity cost adjustment. We all know that what you're trying to do is get the best price you can and hopefully cover your costs.

What I found was when I was talking to people about FVA is you start talking about how derivatives should be accounted for and very quickly you slip into talking about how much the customer should be charged, which is a totally different issue. Obviously, there's all sorts of costs you've got to recover in terms of what you charge the customer.

Where are accountants coming from? As you all know, accountants want you to value derivatives at exit prices. The accounting bodies are quite clear, that the exit prices have nothing to do with your own costs. Exit prices should be related to what's going on in the marketplace. Therefore, your own funding costs can't possibly come into an exit price. If other dealers are using FVA in their pricing, their funding costs may be relevant, but your own funding costs are not relevant. An interesting question is how should we determine exit prices in a world where all dealers are incorporating FVA into their pricing. Should we build into our exit price an average of the funding costs of all dealers or the funding cost of the dealer that gives the most competitive price? You can argue about this, but it is difficult to argue that it is your own funding costs that should be used in accounting.

What we have found is there's a lot of confusion between DVA and FVA, and as I said there's really two distinct parts to DVA. There's the DVA associated with the fact that you may default on your derivatives. That's what we call DVA 1. It's the usual DVA. Your DVA 1 is your counterparty's CVA and vice versa. And then there's what we call DVA 2, which is the fact that you might default on your funding.

Banks have always been uncomfortable with DVA. Even though accounting bodies have approved DVA they dislike the idea of taking their own default risk into account. This has led some banks to replace DVA by FVA. In this context, FVA is sometimes divided into a funding benefit adjustment and a funding cost adjustment with the funding benefit adjustment being regarded as a substitute for DVA.

When you look at what's actually going on right now, banks are all over the place in terms of how they make funding value adjustments. I agree with Damiano that once JP Morgan announced that it is taking account of FVA, then everybody felt they had to do it as well. The correctness of FVA becomes a self-fulfilling prophecy. A bank's auditors are going to say, Everybody else is doing this? Why aren't you doing $i t$ ? Whether or not you believe the models used by everyone else are correct, you have got to use those models to determine accounting values. 
You can have research models for trading, but for accounting you've just got to do what everybody else does. When a critical mass of people move over to doing something, whether it's right or wrong, you've got to do it.

I notice from a recent article in Risk that the Basel committee is getting interested in funding value adjustments. And U.S. regulators are getting interested in funding value adjustments as well. In addition, I can tell you that a few months ago, Alan White and I were invited to FASB to talk to them about funding value adjustments. They have concerns about the use of FVA in accounting. They like derivatives accounting valuations to be based on market prices not on internal costs.

I think we are in a fairly fluid situation here. When JP Morgan has said, We're doing it this way, and we're taking a one-and-half billion dollar hit it is tempting to believe that everyone else will follow suit and that is the end of the story. I don't think it is the end of the story because we have not yet heard from accountants and regulators. Also, I think it is fair to say that the views of banks and the quants that work for them are evolving.

There's some good news. (Maybe it's not good news if you're a quant working for a bank.) The good news is that we're clearly moving to a world where all derivatives are fully collateralised. We're now in a situation where if you deal with another financial institution or another systemically important entity, you've got to be fully collateralised. Dealing with an end user, you don't have to be fully collateralised. But there's a lot of arguments (we talked about some of them at this conference) suggesting that end users will get a better deal if they are fully collateralised.

FVA is not going to be such a big issue going forward. Indeed, I think it's going to fade away as full collateralisation becomes the norm. But no doubt arguments about some other XVAs will continue.

Ralf: Thank you, John. I take away that for PhD students it is wise not to pursue too much research on FVA, then, it might not be worth the effort ...

Audience member: Sorry, just if you'll allow me a little comment. Since the issue of the self-fulfilling prophecy was picked up also by John Hull, just a little comment from a mathematical point of view. If you do mathematics for the application, you need a model. Possibly a true model. So what is a true model? Now, if you do applications for the natural or physical sciences, possibly there is a true model. It is very complicated, and what you do, you choose a model that is a good compromise between representativity and tractability, right, so you can deal with this model and it's still relatively good.

Now we come to social / economic sciences. What is the true model? If, at some point, the majority sort of implicitly uses a sort of model, isn't that all of a sudden the true model that other people should follow, or am I wrong here?

Damiano: Like base correlation, for example?

John: Yes, I don't see it quite that way, though. I think opinions will fluctuate through time. Nearly all large global banks do make funding value adjustments now. There are two or three holdouts, but most of them do.

I think FVA is going to be more of a fad than a truth. I think that in five years' time we could be in the opposite position to today: everybody just decides they don't want to make these funding value adjustments. That's just my own personal opinion. 
One thing I meant to say is that there are interactions between CVA and DVA. If one side defaults, you don't care about the other side defaulting later, and there are a number of other close-out issues. I agree with what Damiano says. Those create a lot of complications. And they are relevant because those are complications in assessing expected cash flows arising from the derivatives portfolio that you have with a counterparty. They're nothing to do with funding. They're to do with expected future cash flows, which are the relevant things to calculate a valuation. It does make the valuation more complicated, but to overlay that with funding adjustments I don't think is correct except insofar as some part of the funding value adjustment is the dead-weight cost I was talking about.

Ralf: Thank you, John. You mentioned valuation, so maybe this is the keyword to hand over to Daniel.

\section{Daniel Sommer}

Daniel: First, John, as you immediately addressed the accounting profession, I'm not an accountant but I work for a firm that does audit and accounting as some part of its business. Are our accountants just people who tell the banks to do what everybody else does? The story is slightly more complicated than that because what accountants are interested in, and I pick up this story about self-fulfilling prophecies, what they are interested in eventually is fair value. And, indeed, for financial instruments that's defined as the exit price. But then the big question is: How do you find out what the exit price actually is?

Because it's not like for all the instruments that we're talking about in this seminar here, it's not something that you can read on Bloomberg or any other data provider. It's nothing that people will tell you in the street immediately. It's rather a complicated exercise to find out what fair value actually is. What would be the exit price at which you could actually exit your position? It's at that point where that whole reasoning comes up with the notion of how other people are thinking about valuing a certain position. How are my counterparties, my potential counterparties in the market, thinking about it? And that gives a bit more sense to the statement Do what everybody else does. Because if everybody else is taking certain aspects of a financial instrument into consideration when valuing this asset, it's very likely that your exit price that you are offered will also take that into consideration. It's for that reason that accountants are interested in what everybody else is doing, and frankly speaking, yes, at KPMG, that was indeed the discussion we had with many banks over the last three/four years where we met the banks in London on various panels to discuss FVA with them. Those were quite open discussions. From one year to the other, we sort of made a roll call and asked who's going to do what next year and when do you think you will be moving to FVA, etc., just to get a feeling for where the market was going in order to have a better understanding of what the market thought fair value would be. In that sense, I think that gives a bit more meaning to accountants telling the banks to do what everybody else is doing. 
Now, coming to the current situation, indeed, I think there is no major bank globally left who has not declared they were doing something on funding valuation adjustments, with a lot of banks having come up with that in their 2014 year-end accounts. So I think the pressure on those banks who have not yet done that is actually rising. That's something which I think is a matter of fact.

I'm happy to comment or give my personal opinion about FVA, and perhaps talk about it by going back to some anecdotal evidence which I came across during the financial crisis. Before that, let me just mention a few more things.

Indeed the regulators become interested in FVA, and I think that there are at least two big issues that will have real effects on the banks that will enter the regulatory discussion or should enter the regulatory discussion. One thing is, indeed, the overlap between FVA and DVA, where many banks are happy to scrap DVA to a certain extent and replace it with FVA because that will have an immediate effect on their available regulatory capital. Because as they do the calculations these days, they offset FVA benefits and FVA costs. Thus to reduce DVA, where they need to deduct DVA from core Tier 1 capital, has a real effect on the bank's balance sheets and profitability calculations regarding regulatory capital.

The other thing people mentioned and it is true: hedging FVA just as is the case with CVA is a complicated issue and involves also hedging the related market risk. And so the question that we have been debating for CVA for a long time already is whether you are allowed to include the market risk hedges in your internal model for market risk or not. We've seen some movements in this direction recently by the regulators, but I think that those are two questions that at least should be quite prominent in the regulatory debate coming up.

That's one thing. The other thing is related to accounting. People quite leisurely mentioned that, well, yes, we need to go from a single deal valuation to portfolio valuation. And indeed for CVA that's absolutely inevitable. If you do that, nevertheless, for an accountant that raises a few uncomfortable questions because it raises the question: What is actually the unit of account? Apparently it's not a single deal. It may be the netting set as far as CVA is concerned, but when you look at funding, the netting set may even be too small, so it may be some sort of funding set, so all the deals that you have in one currency or so. When you look at effects on the balance sheet, do you need to value your whole bank before you can actually value your derivatives correctly? That's a bit of an uncomfortable direction we're going into.

Those are a few comments on things that people have said up to now, but on FVA itself, let me give you a little anecdote that occurred to me during the financial crisis. During the financial crisis, the CFO and CEO of one of our top-ten German banks asked me: Look, all the banks have to reduce the values of their ABS and CDO books. Actually, don't you think that if a book is match-funded, it should be worth more than if a book is not match-funded? And this goes back to the real fundamental question of liquidity risk and whether liquidity should play a role in pricing. And everybody who's read Modigliani and Miller, would say, By no means. That would be the standard answer. Nevertheless, when you come to think about the situation that the banks were in during the financial crisis, actually having a match-funded book gave you at least the option to wait. And there's real value in that option, as the banks 
who were able to wait were able to realise this because much of the write-downs that happened during the financial crisis actually came back as defaults were not as heavy as would have been thought at the time and indicated through the quotes at the peak of the crisis. It wasn't even traded prices at the time; it was basically quotes that banks were valuing their books on.

One might think - a very personal view at this point - one might think that if banks go for match-funding their books, it's like buying a very, very deep out-ofthe-money option that they can then exercise when things get really bad. So that's one comment I would like to make.

The other point is somewhat more disconcerting. What does being liquid mean in a world that has had the experience of the financial crisis? Is it sufficient to say that a bank is liquid if it can generate enough funds through the collateralised inter-bank money market? Or does a bank have to have access to sufficient central bank money to prove that it is liquid? At least the experience of the financial crisis showed the vulnerability of the inter-bank market and the importance of central bank money to keep the system afloat. In that case at least part of the liquidity costs of banks would be due to ensuring it has enough central bank money or assets that can swiftly be turned into the latter. But if that was so then this would change our whole valuation paradigm, which after all is based on the general equilibrium theory and the theory of value by Gérard Debreu and others. In this theory there is no need for a central bank to keep the system working. Therefore, acknowledging the existence of funding costs through the introduction of FVA may have far reaching consequences on the derivatives pricing theory compared to just the calculation of some odd valuation adjustment and quarreling about which funding curve to use to determine an exit price.

Ralf: Thank you, Daniel. John, do you want to comment on this? Is Miller and Modigliani still valid in such an environment?

John: Well, I think it is, but what Modigliani and Miller say is that if you cut the pie up, the sum of the pieces is worth the same as the whole. Now, the question is, who are the potential stakeholders you've got to look at when you cut the pie up.

I agree with pretty much everything that Daniel said. It makes a lot of sense.

Ralf: Christian?

Christian: I have a question maybe from the practitioner's side, also being a little bit of a quant with respect to the exit price, which keeps me puzzling. Just to make that clear, for me there are two prices at least. The exit price, I can realise it only once: by going out of business. There's only one opportunity to realise the exit price. There is, of course, the price which I use in calculating my risk sensitivities, my hedge, which I use in solving my optimal control problem, in my risk management problem.

So, for example, if the exit price would include a tax, there would be some kind of going-out-of-business tax, the exit price would clearly include this tax, but of course as long as I'd like to stay in business I would never charge that tax, and I would not include it in my hedging because it would never occur to me.

What is strange for me is that I believe that the good price for doing the optimal control problem, so how do you hedge and so on, is actually the price which is going 
to concern and not the exit price, but the balance sheet is using the exit price, and it appears to me as if management is always looking at the balance sheet. Isn't there some kind of contradictions? What is the price that should be used to find the optimal path for the company? To make the investment decisions and so on?

Daniel: First of all, it's very clear that what the accounting standards mean by exit price is by no means the price at which the bank would go out of business. It's a going concern still. Of course it's an artificial concept in the sense that you will never ... even if you were to sell just a portfolio of your trading book, you would probably not realise what accountants think of as the fair value because they explicitly rule out including portfolio effects on this fair value.

What this exit price actually means is, two people meet in the market and they agree on a certain price at which to exchange a position without changing the market equilibrium, it has to be small relative to the market.

Christian: For example, for my own bonds, the exit price is my bond value, which obviously includes my funding, and for uncollateralised derivatives it is the derivative valued with some average market funding, and if I take your example of fully matched funding, this is puzzling me because the bonds are on funding and the uncollateralised derivatives are not on funding.

Ralf: I think this goes in the same direction as my question to Damiano about the close-out value-what value to use. I think we probably will not solve this puzzle today. Looking at the time, I would like to thank all of you for your attention. Thank you very much to all panelists, and I suppose there's plenty of time for further discussions during the dinner tonight. Thank you!

\subsection{Acknowledgements, Credits, and Disclaimer}

All statements made in this panel discussion represent the personal views of the participants. Photographs of Damiano Brigo and John Hull by Astrid Eckert; photograph of the panel by Bettina Haas. The transcription of audio tape to text was made by Robin Black. For help with the manuscript we thank Florian Zyprian.

Acknowledgements The KPMG Center of Excellence in Risk Management is acknowledged for organizing the conference "Challenges in Derivatives Markets - Fixed Income Modeling, Valuation Adjustments, Risk Management, and Regulation”.

Open Access This chapter is distributed under the terms of the Creative Commons Attribution 4.0 International License (http://creativecommons.org/licenses/by/4.0/), which permits use, duplication, adaptation, distribution and reproduction in any medium or format, as long as you give appropriate credit to the original author(s) and the source, a link is provided to the Creative Commons license and any changes made are indicated.

The images or other third party material in this book are included in the work's Creative Commons license, unless indicated otherwise in the credit line; if such material is not included in the work's Creative Commons license and the respective action is not permitted by statutory regulation, users will need to obtain permission from the license holder to duplicate, adapt or reproduce the material. 


\section{References}

1. Brigo, D., Morini, M.: Closeout convention tensions, Risk, pp. 86-90 (2011)

2. Brigo, D., Morini, M., Pallavicini, A.: Counterparty Credit Risk, Collateral and Funding: With Pricing Cases for all Asset Classes. Wiley, New York (2013). ISBN 978-0-470-74846-6

3. Brigo, D., Pallavicini, A.: Nonlinear consistent valuation of CCP cleared or CSA bilateral trades with initial margins under credit, funding and wrong-way risks. J. Financ. Eng. 1(1), 1-60 (2014)

4. Pallavicini, A., Perini, D., Brigo, D.: Funding Valuation Adjustment: FVA consistent with CVA, DVA, WWR, Collateral, Netting and re-hyphotecation, working paper (2011)

5. Fries, C.: Mathematical Finance: Theory, Modeling, Implementation. Wiley, New York (2007)

6. Fries, C., Lichtner, M.: Collateralization and Funding Valuation Adjustments (FVA) for Total Return Swaps, working paper (2014)

7. Hull, J., White, A.: The FVA debate, Risk, 25th anniversary edn, pp. 83-85 (2012) 